\title{
Occurrence and multidrug resistance of Campylobacter spp. at duck farms and associated environmental and anthropogenic risk factors in Bangladesh
}

Md. Nasir Uddin ${ }^{1 \dagger}$, Sucharit Basu Neogi ${ }^{2 \dagger}$, Sk Shaheenur Islam', Jannatul Ferdous ${ }^{3}$, Md. Shahidur Rahman Khan', Shinji Yamasaki and S. M. Lutful Kabir ${ }^{1 *}$

\begin{abstract}
Background: The alarming rise in multi-drug resistant (MDR) zoonotic pathogens, including Campylobacter spp., has been threatening the health sector globally. In Bangladesh, despite rapid growth in poultry sector little is known about the potential risks of zoonotic pathogens in homestead duck flocks. The aim of this study was to understand the occurrence, species diversity, and multi-drug resistance in Campylobacter spp., and identify the associated risk factors in duck farms in Bangladesh.

Methods: The study involved 20 duck farms at 6 sub-districts of Mymensingh, Bangladesh. Monthly occurrence of Campylobacter spp. in potential sources at the farms during February-September, 2018, was detected by culture and PCR-based methods. Campylobacter isolates were examined for resistance to different antimicrobials. Risk factors, concerning climatic and environmental disposition, farm management, and anthropogenic practices, of Campylobacter infection were estimated by participatory epidemiological tools.

Results: Occurrence of Campylobacter spp. was detected in overall 36.90\% (155/420) samples, more frequently in drinking water $(60 \%, 30 / 50)$, followed by cloacal swab (37.50\%, 75/200), egg surface swab (35\%, 35/100) and soil of the duck resting places $(30 \%, 15 / 50)$ but was not detected in feed samples $(n=20)$. PCR assays distinguished the majority $(61.30 \%, 95 / 155)$ of the isolates as C. coli, while the rest $(38.70 \%, 60 / 155)$ were C. jejuni. Notably, $41.7 \%$ (25/60) and $31.6 \%$ (30/95) strains of C. jejuni and C. coli, respectively, were observed to be MDR. The dynamics of Campylobacter spp., distinctly showing higher abundance during summer and late-monsoon, correlated significantly with temperature, humidity, and rainfall, while sunshine hours had a negative influence. Anthropogenic management-related factors, including, inadequate hygiene practices, use of untreated river water, wet duck shed, flock age (1-6 months), and unscrupulous use of antimicrobials were identified to enhance the risk of MDR Campylobacter infection.
\end{abstract}

Conclusion: The present study clearly demonstrates that duck farms contribute to the enhanced occurrence and spread of potentially pathogenic and MDR C. coli and C. jejuni strains and the bacterial dynamics are governed by a

\footnotetext{
*Correspondence: Ikabir79@bau.edu.bd

${ }^{\dagger}$ Md. Nasir Uddin and Sucharit Basu Neogi contributed equally to this work

${ }^{1}$ Department of Microbiology and Hygiene, Bangladesh Agricultural University, Mymensingh 2202, Bangladesh

Full list of author information is available at the end of the article
} original author(s) and the source, provide a link to the Creative Commons licence, and indicate if changes were made. The images or other third party material in this article are included in the article's Creative Commons licence, unless indicated otherwise in a credit line to the material. If material is not included in the article's Creative Commons licence and your intended use is not permitted by statutory regulation or exceeds the permitted use, you will need to obtain permission directly from the copyright holder. To view a copy of this licence, visit http://creativecommons.org/licenses/by/4.0/. The Creative Commons Public Domain Dedication waiver (http://creativeco mmons.org/publicdomain/zero/1.0/) applies to the data made available in this article, unless otherwise stated in a credit line to the data. 
combined interaction of environmental and anthropogenic factors. A long-term holistic research at the environmentanimal-human interface would be integral to divulge health risk reduction approaches tackling the spread of Campylobacter spp. from duck farms.

Keywords: Campylobacter, Semi-scavenging duck, Risk factors, Multidrug resistance, Bangladesh

\section{Background}

Along with the huge growth of the human population, and consequently, overexploitation of natural resources, habitat degradation, biodiversity loss, and ecosystem disruption, there have been increasing incidences of zoonotic diseases throughout the world. In Bangladesh, one of the most densely populated countries with rapidly growing poultry sector, ducks are in the second position after chicken to meet people's demand for meat and eggs [1]. Duck farming, as a part of backyard poultry is a significant component of alternative livelihood for the poor communities in this country, and usually the reared ducks are allowed to utilize the semi-scavenging system with less care of veterinary attention $[1,2]$. However, ducks are considered as a potential reservoir of zoonotic infectious organisms, including virus species like the highly pathogenic avian influenza virus (HPAIV) and pathogenic bacteria like Campylobacter spp. [3, 4]. Campylobacter spp. are Gram negative, spiral or slightly curved, microaerophilic, non-spore forming, and motile bacteria with single flagellum at one or both poles [5]. In both developing and developed countries, Campylobacters are frequently isolated among the important enteric pathogens associated with gastroenteritis in human populations, especially in children under 5 years, adolescents aged 15-25 years, and immunocompromised persons [68]. In the case of campylobacteriosis in humans, C. jejuni constitutes an overwhelming majority $(>90 \%)$ of the infections, while C. coli dominates among the rest cases [7]. In Europe, over 200,000 cases of campylobacteriosis have been reported annually, however, the actual number of cases is estimated to be approximately 9 million [8]. Campylobacter spp. have been occasionally reported to inflict Guillain-Barré syndrome, Reactive Arthritis, Miller Fisher syndrome, and Irritable Bowel syndrome [5]. In broiler chicken and cattle, C. jejuni is the dominant species, accounting $>80 \%$ among the isolates of thermophilic Campylobacter spp., whereas C. coli predominates (>90\%) among those from wild ducks and swine [3, 7]. In comparison to extensive research on Campylobacter spp. among the broiler and layer chickens, there have been relatively less investigations on the occurrence and risk factors of this pathogen among the duck flocks, particularly, in developing countries.

Transmission of Campylobacter spp. in human usually happen through consumption of contaminated meat, water and milk products [9]. Apart from unhygienic handling of poultry animals or their edible products, environmental components contaminated with poultry excreta are important risk factors for Campylobacter infections, particularly, at farms and abattoirs [10,11]. A summer peak in the prevalence of Campylobacter-positive poultry flocks coinciding with increased infection in humans has been reported in a number of countries $[12,13]$. Variation in temperature, 2-6 weeks prior to the reported infections has been notified as to the most important climatic predictor of campylobacteriosis incidence, which may be also influenced by sunshine hours, and relative humidity [14-16].

In the recent decades, the worldwide rise in multi-drug resistance (MDR) among the microbial pathogens at an alarming frequency have imposed a significant challenge to the health of humans and animals. Large-scale applications of antimicrobials, mostly in an imprudent manner, in medical, agriculture, livestock, and poultry sectors are thought to induce selective pressure favoring the occurrence of MDR pathogens [17, 18]. Although Campylobacter infections are mostly self-limiting, antimicrobial agents, including erythromycin, tetracycline, aminoglycosides, and fluoroquinolones are often used, particularly, for immunocompromised patients [18-20]. In Bangladesh, despite increasing efforts by the Government to promote the prudent use of antimicrobials, [21] these agents are still widely applied. In this densely populated country, MDR infections from the emergent poultry sector is a major concern to public health. Consequently, Campylobacter isolates showing an increasing frequency of resistance to antimicrobials, including nalidixic acid, tetracycline, fluoroquinolones, and macrolides, have been reported for both in healthy animals and human cases of gastroenteritis and diarrhea [10,11, 22-24].

In Bangladesh, there remains a lack of systematic information on the occurrence, socio-environmental risk factors, and multi-drug resistance of Campylobacter spp. in ducks and wild birds in this country. Various studies have noted that apart from climatic influences, other factors related to farm management, e.g., unhygienic practices, increasing age of birds, flock size, insufficient sunlight or ventilation, and even interface with wild birds could influence the occurrence of Campylobacter spp. in poultry flocks [11, 24-26]. Despite its natural link with Campylobacter, duck or duck farms as 
a source of campylobacteriosis in humans has remained unexplored in Bangladesh. This study aimed to understand the occurrence of Campylobacter spp., and their drug resistance patterns, in semi-scavenging duck flocks, reared at household premises in this country. Moreover, the sociodemographic traits, farm management practices and climatic factors that may contribute to increased occurrence of Campylobacter spp. were also assessed to identify the major socio-environmental drivers and risk factors of these potentially harmful bacteria associated with duck farming.

\section{Methods}

\section{Study sites}

The study involved socio-environmental surveillance at 20 semi-scavenging duck farms in 6 sub-districts (Mymensingh Sadar, Muktagachha, Phulpur, Tarakanda, Gouripur and Trisal) of Mymensigh district in Bangladesh (Fig. 1). The study farms were selected based on consultation with local livestock offices, with the inclusion criteria: number of reared ducks at least 200, and a single farm from each village. At least 2 farms from each sub-districts were selected.

\section{Collection of animal and environmental samples}

Samples representing the potential sources of Campylobacter spp. in duck farms were collected during AprilAugust, 2018 for microbiological analysis. Considering an expected prevalence of Campylobacter spp. in 50\% of the ducks, a sample size of 385 at least was needed for a $95 \%$ confidence interval, according to the following formula [27].

$$
n=Z^{2} p(1-p) / d^{2}
$$

where $\mathrm{n}$ represents the sample size needed; $Z^{2}$, the Z-score at 95\% confidence interval (1.96); p, the expected proportion (50\%) of Campylobacter spp.; and $d$, the expected margin of error (0.05).

However, in this cross-sectional study, five kinds of samples at various proportions were collected at each of the 20 duck farms, yielding a total of 420 samples. The sampling strategy for different contamination sources was in accordance to the observed trend of Campylobacter occurrence at poultry farms in this region [11]. The sample diversity represented potential contamination sources: cloacal swab (CS), egg surface swabs (ES), the

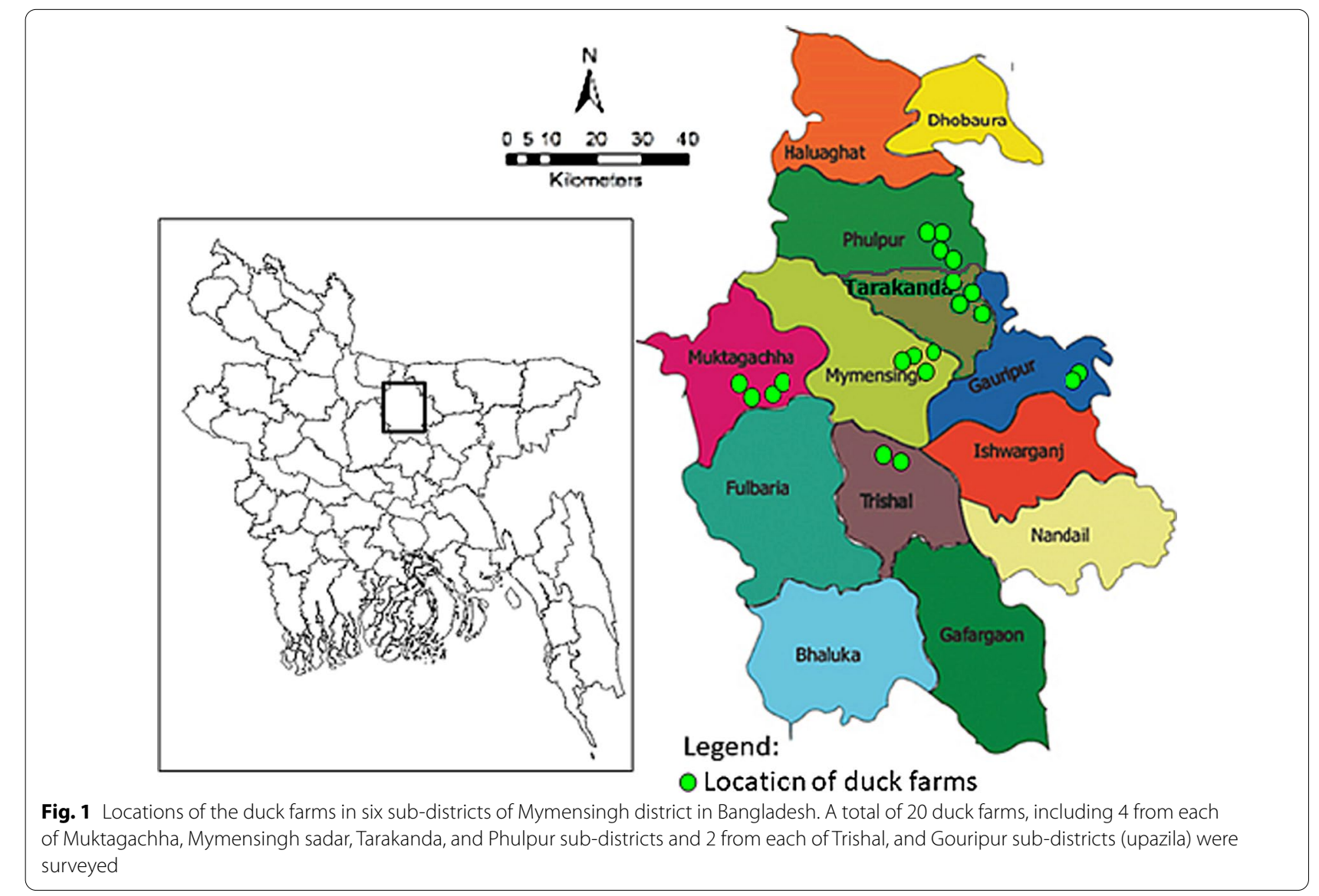


soil of the duck resting places (S), drinking water (DW), and feed (F). At individual farm level, category-wise sample numbers were CS $(\mathrm{n}=10)$, ES $(\mathrm{n}=5), \mathrm{S}(\mathrm{n}=2-4)$, DW $(n=2-4)$ and $F(n=1)$, respectively. Overall, from all the duck farms, a total of 200, 100, 50, 50, and 20 samples of CS, ES, S, DW, and F, respectively, were obtained.

During each sampling of DW, S, and F, at least three sub-samples were randomly collected and pooled together. The source of DW was either tube-well or natural surface water of the river/canal. Feed samples represented the commercially formulated products (a mixture of ingredients: cereal grains and plant or animal by-products, vitamin and mineral supplements). These commercial feeds were regularly served to the ducks, which were also allowed for natural scavenging. The ES samples were obtained from the newly laid eggs. Aseptic measures were followed while collecting these samples in various amounts, i.e., 3-5 g (wet weight) for CS and ES, $100 \mathrm{~g}$ for soil and feed samples, and $500 \mathrm{~mL}$ for DW. The swab samples were collected in a sterile cotton swabs and preserved immediately in Cary-Blair transport media while the rest of the samples were kept in sterile plastic containers. All the samples were transported in an insulated foam box with a cold chain (temperature, $4-6{ }^{\circ} \mathrm{C}$ ) and processed within $6 \mathrm{~h}$ of collection.

\section{Isolation and identification of Campylobacter spp. by culture based methods}

Isolation of Campylobacter spp. was carried out following the filtration-based culture method [28]. In brief, the swab samples $(1 \mathrm{~g}$ each) and soil or feed samples (10 g each) were suspended in 1 and $10 \mathrm{~mL}$, respectively, of sterile phosphate buffer saline (pH 7.4). A $100 \mu l$ portion, in three replicates, of the suspensions was spread onto a membrane filter (mixed cellulose ester type, $0.45 \mu \mathrm{m}$ pore size, $47 \mathrm{~mm}$ diameter; Sartorius Stedim Biotech, Germany). In the case of DW, at least three replicates of a $100 \mathrm{~mL}$ portion were filtered. After sample inoculation, each of the membrane filters was overlaid on a blood agar medium (blood base agar no. 2; HiMedia, India), supplemented with $5 \%$ defibrinated sheep blood, and allowed to stand for $30 \mathrm{~min}$ at room temperature. The filter paper was then removed and the blood agar plate was incubated at $37{ }^{\circ} \mathrm{C}$ for $48 \mathrm{~h}$ within a thin-type jar in microaerophilic condition $\left(5 \% \mathrm{O}_{2}, 10 \% \mathrm{CO}_{2}\right.$, and $\left.85 \% \mathrm{~N}_{2}\right)$ using AnaeroPouch ${ }^{\circledR}$-MicroAero (Mitsubishi Gas Chemical Co., Inc.). Presumptive colonies of Campylobacter, which appear grey, flat, and irregularly spreading, were screened from the incubated blood agar medium and sub-cultured on the same medium following the procedures described above. The pure culture of each isolate was then subjected to Gram's staining and observed under a microscope. Campylobacter-like isolates, which appeared Gram-negative and curve- or spiral-shaped cells, were subjected to species-differentiating biochemical assays, including motility test, catalase, oxidase, and hippurate hydrolysis, according to standard procedures [5].

\section{PCR-based confirmation of Campylobacter spp.}

DNA templates from presumptive isolates of Campylobacter spp., detected by culture-based methods, were prepared following the boiling method [29]. The 16S rRNA gene-based PCR was performed for the identification of the genus Campylobacter using primers and thermal conditions according to Samosornsuk et al. [30]. Species-specific detection of C. jejuni was done following a previously established hippuricase gene-based (hipO) PCR assay [31], with a slight adjustment of thermal condition. The identity of $C$. coli was confirmed following the $c d t C$ gene-based multiplex PCR assay [32]. All primers (Macrogen Inc., Korea) and thermal conditions for the PCR assays used in this study are described in Table 1. In each PCR, the reaction mixture $(25 \mu \mathrm{l})$ was prepared by mixing $12 \mu \mathrm{l}$ master mixtures (Promega, USA), $1 \mu \mathrm{l}$ of

Table 1 List of primers and thermal condition used for molecular identification of Campylobacter species

\begin{tabular}{|c|c|c|c|c|c|c|c|}
\hline \multirow[t]{2}{*}{ Primer } & \multirow[t]{2}{*}{ Sequence $\left(5^{\prime}-3^{\prime}\right)$} & \multirow[t]{2}{*}{ Target } & \multirow{2}{*}{$\begin{array}{l}\text { Amplicon } \\
\text { size (bp) }\end{array}$} & \multicolumn{3}{|c|}{ PCR condition (30 cycle) } & \multirow[t]{2}{*}{ References } \\
\hline & & & & Denature & Annealing & Extension & \\
\hline $\begin{array}{l}\text { 16S9F } \\
16 \mathrm{~S} 1540 \mathrm{R}\end{array}$ & $\begin{array}{l}\text { GAGTTTGATCCTGGCTC } \\
\text { AAGGAGGTGATCCAGCC }\end{array}$ & 16S rRNA & 1530 & $94^{\circ} \mathrm{C}, 30 \mathrm{~s}$ & $47^{\circ} \mathrm{C}, 30 \mathrm{~s}$ & $72^{\circ} \mathrm{C}, 90 \mathrm{~s}$ & Samosornsuk et al. [21] \\
\hline $\begin{array}{l}\text { HIP400F } \\
\text { HIP1134R }\end{array}$ & $\begin{array}{l}\text { GAAGAGGGTTTGGGTGGTG } \\
\text { AGCTAGCTTCGCATAATAACTTG }\end{array}$ & hipO gene & 735 & $94^{\circ} \mathrm{C}, 30 \mathrm{~s}$ & $55^{\circ} \mathrm{C}, 30 \mathrm{~s}$ & $72^{\circ} \mathrm{C}, 45 \mathrm{~s}$ & Linton et al. [22] \\
\hline $\begin{array}{l}\text { Cj-cdtCU1 } \\
\text { Cj-CdtCR2 }\end{array}$ & $\begin{array}{l}\text { TTTAGCCTTTGCAACTCCTA } \\
\text { AAGGGGTAGCAGCTGTTAA }\end{array}$ & $C j-c d t C$ & 524 & $94^{\circ} \mathrm{C}, 30 \mathrm{~s}$ & $53^{\circ} \mathrm{C}, 30 \mathrm{~s}$ & $72^{\circ} \mathrm{C}, 30 \mathrm{~s}$ & Asakura et al. [23] \\
\hline $\begin{array}{l}\text { Cc-CdtCU1 } \\
\text { Cc-CdtCR1 }\end{array}$ & $\begin{array}{l}\text { TAGGGATATGCACGCAAAG } \\
\text { GCTTAATACAGTTACGATAG }\end{array}$ & Cc-cdtC & 313 & & & & \\
\hline $\begin{array}{l}\text { CfspCU2 } \\
\text { CfspCR1 }\end{array}$ & $\begin{array}{l}\text { AAGCATAAGTTTTGCAAACG } \\
\text { GTTTGGATTTTCAAATGTTCC }\end{array}$ & $C f-c d t C$ & 397 & & & & \\
\hline
\end{tabular}

Cj: C. jejuni; Cc: C. coli; Cf: C. fetus 
each forward primer (10 pmol), $1 \mu$ l each reverse primer $(10 \mathrm{pmol}), 3 \mu \mathrm{l}$ DNA template and rest deionized water. The PCR reactions were carried out using a thermocycler (Astec, Japan). PCR products $(5 \mu \mathrm{l})$ were analyzed by $2 \%$ agarose (Invitrogen, USA) gel electrophoresis, followed by staining of the gel with ethidium bromide $\left(0.5 \mu \mathrm{g} \mathrm{mL}^{-1}\right)$ and de-staining with distilled water, $10 \mathrm{~min}$ each. Afterward, the gel images with PCR amplicons were captured using a UV transilluminator (Biometra, Germany).

\section{Antimicrobial susceptibility test}

All isolates of C. jejuni and C. coli were tested for their antimicrobial susceptibility by disk diffusion method [24]. Eight commonly used antimicrobial agents at standard doses were used: amoxicillin (AMX) $(30 \mu \mathrm{g})$, azithromycin (AZM) $(30 \mu \mathrm{g})$, ciprofloxacin (CIP) $(5 \mu \mathrm{g})$, erythromycin (ERY) $(30 \mu \mathrm{g})$, gentamycin (GEN) $(10 \mu \mathrm{g})$, norfloxacin (NOR) $(10 \mu \mathrm{g})$, streptomycin (STR) $(10 \mu \mathrm{g})$, and tetracycline (TET) $(30 \mu \mathrm{g})$ (HiMedia, India). Initially, cells from freshly grown broth-culture (Mueller-Hinton broth, HiMedia, India) of each Campylobacter isolate were harvested by centrifugation and then suspended in sterile normal saline ( $\mathrm{pH}$ 7.4). The turbidity of each cell suspension was adjusted to a 0.5 McFarland standard. A portion of the cell suspension was uniformly inoculated, using a sterile cotton swab, on the entire surface of Muller Hinton agar (HiMedia, India), supplemented with 5\% defibrinated sheep blood, to produce a confluent lawn of bacterial growth. After drying of the inoculum, 4 antimicrobial discs were placed on each agar plate, which was then incubated in the inverted position at $37^{\circ} \mathrm{C}$ for $48 \mathrm{~h}$ under microaerophilic conditions $\left(5 \% \mathrm{O}_{2}, 10 \% \mathrm{CO}_{2}\right.$, and $85 \% \mathrm{~N}_{2}$ ). The zone of growth inhibition (diameter) of each antimicrobial agent was evaluated according to the interpretative criteria as described by the Clinical and Laboratory Standards Institute [33]. E. coli strain ATCC 25,922 was used as a quality control organism. The results were confirmed by conducting at least two replicates of each disc diffusion experiment.

\section{Surveillance on sociodemographic status, farm management and climatic factors}

Participatory epidemiological (PE) methods [34], including semi-structured interviews, direct observation and focus group discussions (FGDs) were conducted during April-August, 2018 to understand the variations in sociodemographic status and farm management practices that may influence the occurrence of Campylobacter spp. in the semi-scavenging duck flocks. During each FGD, the participation of at least three duck farmers, including the owner, for each of the selected farms $(n=20)$ was ensured. Response to individual queries was attained through consensus among the participants. Prior to each survey, conducted by an experienced team comprised of a couple of veterinarians, the study objectives were explained and verbal consent was obtained from the participants. A total of 20 FGDs, one for each selected farm, were conducted according to the standard procedures [35]. Semi-structured questionnaire-based surveillance was made to understand potential risk factors in the duck farms. In this purpose, farm management, hygiene, and environment-related variables, e.g., number, and age of the reared ducks, scavenging sites, type of feed, source of drinking water, floor condition, sunlight and ventilation facilities, cleaning of the floor and feeder, disinfectants use, hand washing, handling of ducks, veterinary health care facilities, use of antimicrobials and vaccines, duck waste disposal, and wild animal/bird-duck interactions were considered (see Additional file 1). Sociodemographic information, e.g., profession, education, training, and experience in duck rearing, were also collected. Results obtained from PE methods were verified by direct observations and recorded in pre-formatted questionnaires in hard copies.

Among the climatic variables, daily data of temperature (minimum, mean, and maximum values), rainfall, relative humidity, and sunshine hours of the study region (Mymensingh District) for the tenure January-September, 2018, were obtained from the archives of AccuWeather (https://www.accuweather.com/). Climatic data were transformed into monthly average and compared with the concurrent occurrence of Campylobacter spp. in different components of the duck farms.

\section{Data management and statistical analyses}

Data were imported into Microsoft Excel 10 (Microsoft Corporation, Redmond, WA, USA) spreadsheet from the hard copies, and cleaned, coded, and checked for the integrity of the data set. Descriptive statistics with proportion percentage and $95 \%$ confidence interval (CI) of the data representing variations in socio-environmental conditions and bacterial occurrences were performed using the Epi info 7 software [36].

The occurrence of Campylobacter for a particular month were compared with overall average values for the concurrent and preceding months of each climatic factor since the bacterial occurrence in poultry was reported to be influenced by climatic variations at the time lag of 2-5 weeks prior [14-16]. The proportion of the farm samples of each category contaminated with Campylobacter spp. was compared. Correlation and linear regression analysis between the occurrence of Campylobacter spp. and individual climatic factors were performed using 'Xact' (ver. 7.21d, SciLab GmbH, St. Yrieix, France). Significant association (considering $\mathrm{p}<0.05$ ) between the 
prevalence of Campylobacter species and any individual factors related to farm management was determined by the Chi-square test using Statistica (ver. 10.0, StatSoft Inc., USA).

The antimicrobial susceptibility profile of the bacterial isolates was evaluated according to their differentiation into three independent groups, i.e., resistant, intermediate, and susceptible. MDR trait was defined as bacterial strains showing resistance against at least one antimicrobial agent in three or more antimicrobial classes [37]. A descriptive comparison of resistant patterns of Campylobacter strains with respect to diversity in sources and/ or anthropogenic factors was performed using mean/ median and standard deviation, and also in the form of the box plots. Differences in the patterns and/or occurrence of antibiotic resistance in Campylobacter spp. (C. coli and C. jejuni) were calculated by the Paired Samples t-test. A 'p' value of $<0.05$ was considered significant.

\section{Result}

\section{Isolation, identification and occurrence of Campylobacter}

spp.

Of 420 samples (N) collected from 20 duck farms Campylobacter spp. was detected and isolated from $36.90 \%$ (95\% CI $=32.27-41.72 \%)$ samples by selective culture, followed by $16 \mathrm{~S}$ rRNA gene-based genus-specific PCR method (see Additional file 2 showing gel images of representative PCR products).

Among different categories of samples from the duck farms, the contamination of Campylobacter spp., was detected more frequently in drinking water $(60 \%, 30 / 50)$, followed by cloacal swabs $(37.50 \%, 75 / 200)$ and egg surface swab $(35 \%, 35 / 100)$ (Table 2). Among the soil samples collected from the duck resting places $30 \%(15 / 50)$ were detected positive but all feed samples $(n=20)$ were found to be negative for Campylobacter spp. Depending on sample size, the $95 \% \mathrm{CI}$ for the positive detection rate was estimated to deviate ca. 7-15\%, the higher the sample number the lower the percentage deviation (Table 2).

Species-specific detection by PCR assays could differentiate the isolated strains into two species: $C$. coli and C. jejuni in $22.62 \%(95 / 420,95 \% \mathrm{CI}=18.70-26.92 \%)$ and $14.28 \%(60 / 420,95 \% \mathrm{CI}=11.08-18 \%)$ of the total samples, respectively. Campylobacter isolates which were positive in the biochemical assay for hippurate hydrolysis also yielded positive in hippuricase (hipO) gene-based PCR, confirming their identity as $C$. jejuni. On the other hand, all isolates of Campylobacter producing negative results in hippurate hydrolysis test were identified as $C$. coli by $c d t C$ gene based multiplex PCR (see Additional file 2). Overall, among the isolated strains $(n=155)$, an almost two-third portion $(\mathrm{n}=95)$ were identified as C. coli while the rest were $C$. jejuni. In drinking water
Table 2 Summary of the occurrence of Campylobacter species isolated from different type of samples of selected semiscavenging duck farms

\begin{tabular}{lcl}
\hline Sample (N)/Species & Positive (n) & Occurrence (95\% Cl) \\
\hline Cloacal swab (200) & & \\
$\quad$ Campylobacter spp. & 75 & $37.50(30.78-44.60)$ \\
C. jejuni & 29 & $14.50(9.93-20.16)$ \\
C. coli & 46 & $23(17.35-29.47)$ \\
Egg surface swab (100) & & \\
Campylobacter spp. & 35 & $35(25.73-45.18)$ \\
C. jejuni & 13 & $13(7.10-21.20)$ \\
C. coli & 22 & $22(14.33-31.39)$ \\
Soil of the duck resting places (50) & & \\
Campylobacter spp. & 15 & $30(17.86-44.60)$ \\
C. jejuni & 6 & $12(4.53-24.31)$ \\
C. coli & 9 & $18(8.57-31.43)$ \\
Water (50) & & \\
Campylobacter spp. & 30 & $60(45.17-73.60)$ \\
C. jejuni & 12 & $24(13.06-38.16)$ \\
C. coli & 18 & $36(22.91-50.80)$ \\
Feed (20) & 0 & 0 \\
Overall (420) & & \\
Campylobacter spp. & 155 & $36.9(32.27-41.72)$ \\
C. jejuni & 60 & $14.28(11.08-18)$ \\
C. coli & 95 & $22.62(18.70-26.92)$ \\
\hline Clconfidence & &
\end{tabular}

$\mathrm{Cl}$ confidence interval

samples $(\mathrm{n}=50), 24 \%(95 \% \mathrm{CI}=13.06-38.16 \%)$ and $36 \%$ (95\% CI $=22.91-50.80 \%)$ were observed to be contaminated with $C$. jejuni and C. coli, respectively. The higher prevalence of contamination by $C$. coli than $C$. jejuni was also observed to occur at a similar proportion in all other kinds of samples (Table 2).

\section{Antimicrobial resistance pattern of $C$. jejuni and C. coli}

In case of the isolated strains of $C$. jejuni $(\mathrm{n}=60)$, all were observed to be resistant to amoxicillin (Fig. 2). Among these strains, $58.33 \%(\mathrm{n}=35)$ showed resistance against erythromycin, while $33.33 \%(n=20)$ were resistant to both streptomycin and gentamicin, and $16.67 \%(\mathrm{n}=10)$ to both tetracycline and azithromycin. On the other hand, of 95 strains of $C$. coli, $94.74 \%(\mathrm{n}=90)$ exhibited resistant trait for amoxicillin, $52.63 \%(\mathrm{n}=50)$ for both erythromycin and streptomycin, and $15.78 \%(\mathrm{n}=15)$ for tetracycline (Fig. 2). The observed trend in the percentage occurrence of resistant traits was mostly similar for both the C. jejuni and C. coli strains. However, a more frequent occurrence of resistance to streptomycin was observed for the C. jejuni strains in comparison to C. coli. In the case of gentamicin, a higher frequency of 

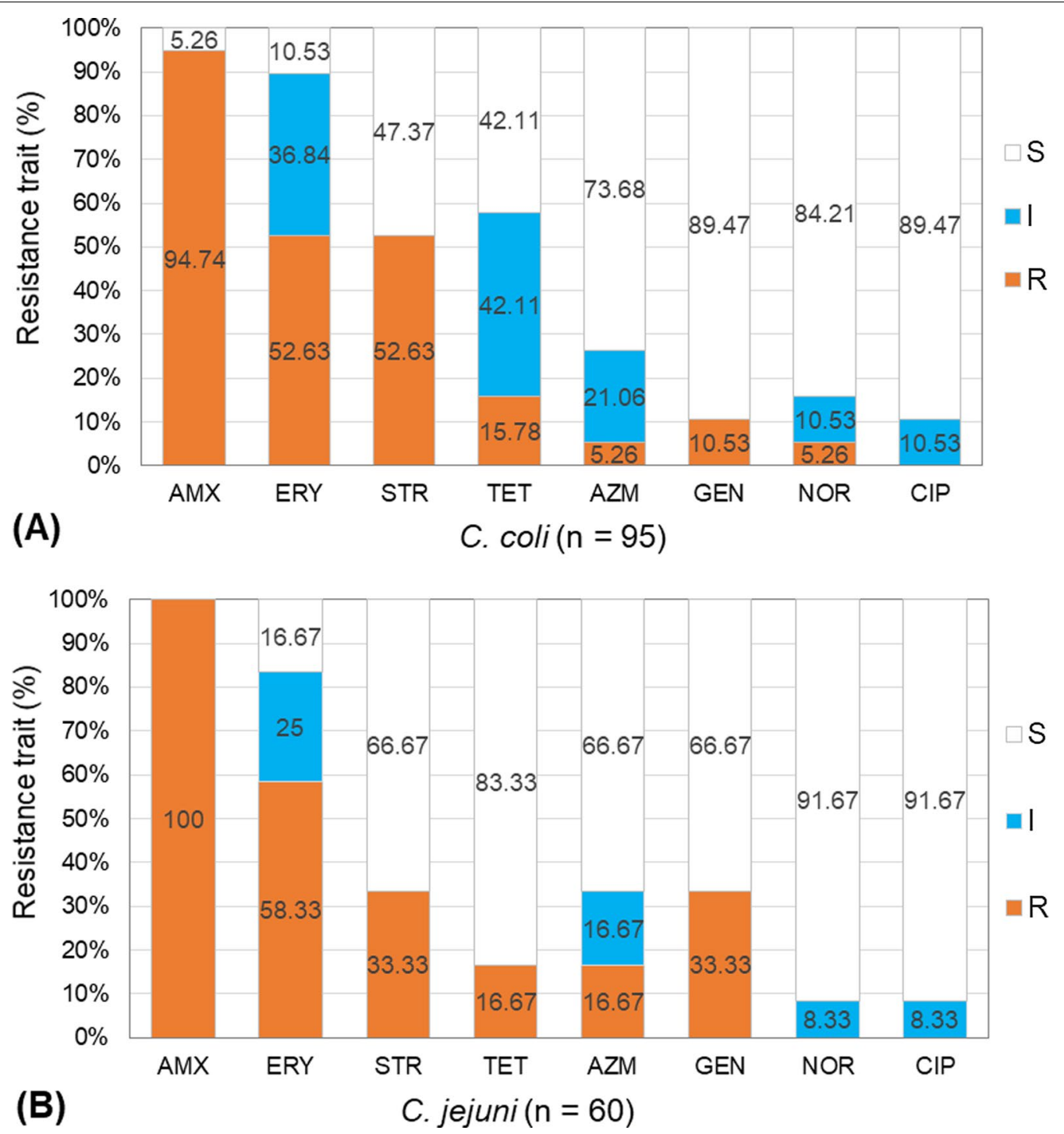

Fig. 2 Antimicrobial resistance traits of $\mathbf{A}$ C. coli, and $\mathbf{B}$ C. jejuni strains isolated from duck farms. Eight selected antimicrobial agents were checked

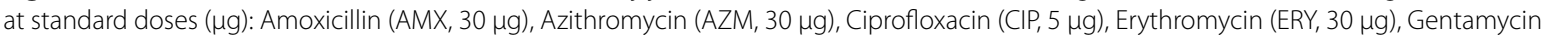
(GEN, $10 \mu \mathrm{g})$, Norfloxacin $(\mathrm{NOR}, 10 \mu \mathrm{g})$, Streptomycin $(\mathrm{STR}, 10 \mu \mathrm{g})$, and Tetracycline $(\mathrm{TET}, 30 \mu \mathrm{g})$. The resistance traits were categorized into three categories: susceptible (S), intermediate (I), and resistant (R) according to Clinical and Laboratory Standards Institute (CLSI, 2016)

resistance for the C. coli strains (33.33\%) in comparison to $C$. jejuni (10.5\%) was notable.

Out of 60 isolated strains of C. jejuni, only $8.33 \%(n=5)$ were resistant to one agent (AMX), while $33.33 \%(n=20)$ were resistant to 2 agents in different categories (AMXGEN, AMX-ERY, AMX-STR, and AMX-TET) (Table 3). Multidrug resistance, i.e., co-resistance to at least three types of antimicrobials were observed for a total of about $42 \%$ strains of C. jejuni. Among these MDR strains, resistance against 3 antimicrobials, differentiated into two patterns (AMX-AZM-ERY and AMX-ERY-STR) were observed for $16.66 \%$ strains of C. jejuni, while $25 \%$ of them were resistant to 4 agents, differentiated into three patterns (AMX-ERY-STR-TET, AMX-AZM-ERYGEN and AMX-ERY-GEN-STR). Among the 95 strains of C. coli, $15.8 \%(\mathrm{n}=15)$ were resistant to one antimicrobial agent (AMX or ERY), whereas almost half portion $(47.37 \%)$ were resistant to two antimicrobial agents, differentiated into five patterns (AMX-TET, AMX-ERY, AMX-NOR, AMX-STR, and AMX-GEN) (Table 3). Occurrence of MDR strains were observed among a total of $36.84 \%(n=35)$ strains, with resistance to three antimicrobial agents of one pattern (AMX-ERY-STR) and four agents of different combinations (AMX-ERY-STR-TET, 
Table 3 Antimicrobial resistance profile of C. jejuni and C. coli isolates from duck farms

\begin{tabular}{|c|c|c|c|c|}
\hline Campylobacter spp & $\begin{array}{l}\text { Category of resistance (against one } \\
\text { or multiple antimicrobials) }\end{array}$ & Resistance patterns $^{1}$ & No. (\%) of strains & $\begin{array}{l}\text { No. (\%) of } \\
\text { multidrug } \\
\text { resistant isolates }\end{array}$ \\
\hline \multirow[t]{10}{*}{ C. jejuni $(\mathrm{n}=60)$} & Against one & $A M X$ & $5(8.33)$ & $25(41.67)$ \\
\hline & Against two & AMX-GEN & $10(16.67)$ & \\
\hline & & AMX-ERY & $10(16.67)$ & \\
\hline & & AMX-STR & $5(8.33)$ & \\
\hline & & AMX-TET & $5(8.33)$ & \\
\hline & Against three & AMX-ERY-STR & $5(8.33)$ & \\
\hline & & AMX-AZM-ERY & $5(8.33)$ & \\
\hline & Against four & AMX-ERY-STR-TET & $5(8.33)$ & \\
\hline & & AMX-AZM-ERY-GEN & $5(8.33)$ & \\
\hline & & AMX-ERY-GEN-STR & $5(8.33)$ & \\
\hline \multirow[t]{11}{*}{ C. coli $(n=95)$} & Against one & AMX & $10(10.53)$ & $35(36.84)$ \\
\hline & & ERY & $5(5.26)$ & \\
\hline & Against two & AMX-STR & $20(21.05)$ & \\
\hline & & AMX-ERY & $10(10.53)$ & \\
\hline & & AMX-NOR & $5(5.26)$ & \\
\hline & & AMX-TET & $5(5.26)$ & \\
\hline & & AMX-GEN & $5(5.26)$ & \\
\hline & Against three & AMX-ERY-STR & $15(15.79)$ & \\
\hline & Against four & AMX-ERY-STR-TET & $10(10.53)$ & \\
\hline & & AMX-AZM-ERY-GEN & $5(5.26)$ & \\
\hline & & AMX-ERY-GEN-STR & $5(5.26)$ & \\
\hline
\end{tabular}

${ }^{1}$ Antimicrobial resistance at standard doses ( $\left.\mu \mathrm{g}\right)$ : Amoxicillin (AMX, $\left.30 \mu \mathrm{g}\right)$, Azithromycin (AZM, $\left.30 \mu \mathrm{g}\right)$, Ciprofloxacin (CIP, $\left.5 \mu \mathrm{g}\right)$, Erythromycin (ERY, $\left.30 \mu \mathrm{g}\right), \mathrm{Gentamycin}$ (GEN, $10 \mu \mathrm{g})$, Norfloxacin (NOR, $10 \mu \mathrm{g})$, Streptomycin (STR, $10 \mu \mathrm{g})$, and Tetracycline (TET, $30 \mu \mathrm{g})$

AMX-E-GEN-STR, AMX-AZM-ERY-GEN) in $15.8 \%$ and $21.05 \%$ strains, respectively, of $C$. coli. Overall, multidrug-resistant Campylobacter spp., considering those showing resistance to at least three or more antimicrobial classes, were observed to constitute ca. $38.70 \%$ (60/155) of the isolated strains. Intermediate resistant isolates, considered as a group independent from those of resistant and susceptible isolates, were observed for erythromycin, tetracycline, azithromycin, norfloxacin, and ciprofloxacin, with a more frequent occurrence in $C$. coli than C. jejuni (Fig. 2).

\section{Climatic variations and Campylobacter dynamics in duck farm samples}

The monthly occurrence, i.e., overall isolation rate in different samples, of Campylobacter spp. in duck farms was observed to be influenced by the variations in temperature, humidity, sunshine hours, and rainfall in the localities. The trend of climatic influence on the bacterial occurrence was observed to be similar among different types of samples with variable isolation rates (see Additional file 3 showing the monthly isolation rates of Campylobacter spp. in different samples). The monthly occurrence of Campylobacter spp. in duck farm samples showed an increasing trend, ca. 17-49\%, accompanied by the rise in temperature from April to June (Fig. 3A). However, Campylobacter abundance showed a drastic decrease in July, with an overall isolation rate of $25 \%$ in the collected samples. This was likely a consequence of the dilution impact of monsoon-driven intense rainfall during June-July. However, a significant increase in Campylobacter occurrence, yielding the highest isolation rate of ca. $55 \%$ for overall samples, was observed for the month of August. A large-scale preponderance of Campylobacter spp. during this late monsoon period coincided with a warm and humid climate but comparatively low amount of rainfall and less duration of sunshine hours (Fig. 3A). The monthly mean values of temperature minimum (Tmin), obtained from its daily values, represented better the temperature variation in comparison to its maximum (Tmax) and average (Tavg) values. Statistical analysis comparing the bacterial isolation rate with individual climatic factors showed that the dynamics of Campylobacter spp. was significantly correlated with Tmin $(\mathrm{p}=0.028, \mathrm{r}=0.60)$ and humidity $(\mathrm{p}=0.026$, $r=0.65)$. On the other hand, rainfall and sun shine hours showed a positive and negative influence, respectively, on Campylobacter occurrence, however, in both cases, the 

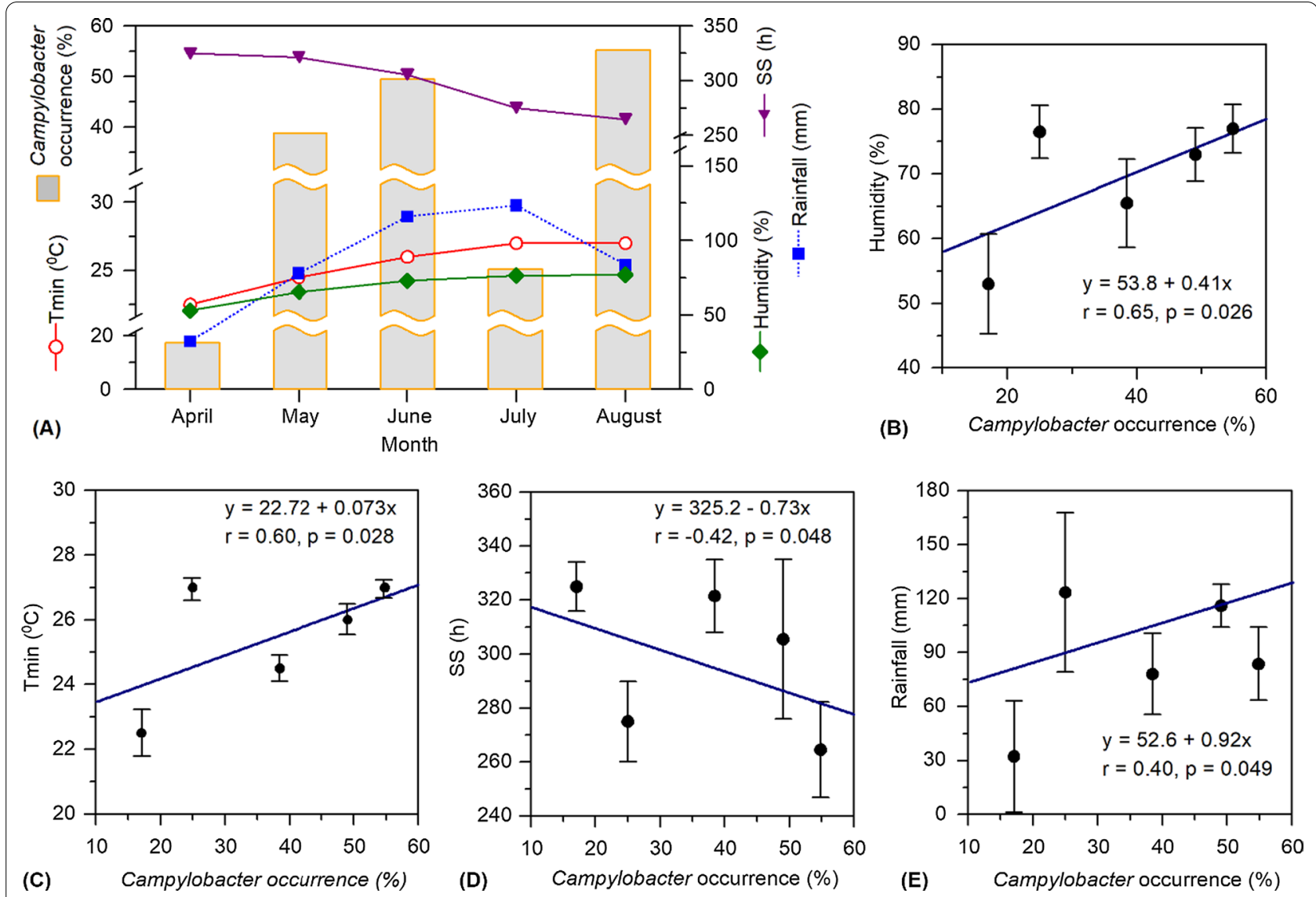

Fig. 3 Influence of climatic factors on the occurrence of Campylobacter spp. in samples collected from the selected duck farms. A Monthly variations in the mean values of the climatic factors and Campylobacter abundance in different samples of the duck farms. Each of the mean values was computed as the average of daily values of the month compared and its preceding one. The monthly occurrences of Campylobacter spp. represent the bacterial overall isolation rate (\% abundance) for different types of samples, i.e., cloacal swab $(n=20-50)$, egg surface swab $(n=10-25)$, soil of the duck resting places $(n=5-14)$ and drinking water $(n=5-14)$. B-E Correlations between the occurrence of Campylobacter spp. and climatic factors. In each figure, the diagonal line represents linear regression between the two parameters, and the relevant statistical information, including regression equation, $r$ - and $p$-values are shown for each correlation. Standard deviations of the mean values of each climatic factor are shown as vertical bars. Tmin and SS indicate temperature minimum and sun shine hours, respectively

significance level was comparatively low and the standard deviation of monthly data was relatively high (Fig. 3B-E).

\section{Duck farm demographics}

Of 20 duck farms, a total of 57 representatives who were directly involved in farm management were interviewed. These farm managers included the owners $(35.10 \%$, $\mathrm{n}=20)$, his/her spouse $(29.82 \%, \mathrm{n}=17)$, son $(17.54 \%$, $\mathrm{n}=10)$ and hired employees $(17.54 \%, \mathrm{n}=10)$. Approximately $25 \%$ of the duck rearers had no formal education, while ca. $23 \%$ of them had completed schooling up to primary level, and the rest had education level between class VI and class XII. Most of the farmers $(94.74 \%, n=54)$ had no training on duck farming, especially, farm management, biosecurity, and personal hygiene and sanitation practices. Approximately two-third $(n=37,64.91 \%)$ of the informants had 1 to 5 years of experience in duck rearing, while only a few of them $(n=9,15.79 \%)$ had such experience over 10 years (see Additional file 4 for details).

\section{Farm management practices and factors influencing Campylobacter occurrence}

Most of the farms $(n=16,80 \%)$ were rearing the 'Khaki Kemble' breed of ducks, while a few $(n=2,10 \%)$ had the 'Choruy' breed and rest $(\mathrm{n}=2,10 \%)$ of the farms rearing both types. The surveyed farms had variable conditions and practices related to farm management which have been summarized in Additional file 5. The number of reared ducks was small (200-300 ducks) in $40 \%(\mathrm{n}=8)$, medium (300-750 ducks) in 30\% $(\mathrm{n}=6)$ and large $(750-$ 1500 ducks $)$ in $30 \%(n=6)$ of the farms. More than half portion, $55 \%(n=11)$, of the farms had ducks of young ages (1-5 months), whereas the rest other farms $(n=9$, 
45\%) had matured ducks (age 10-15 months) capable of egg production. The sources of drinking water were tube-well water $(40 \%, \mathrm{n}=8)$ and surface water of river or canal $(60 \%, n=12)$. More than two-third portion of the farms $(n=14,70 \%)$ had provision of scavenging feed from watershed and paddy field, however, in other farms, the scavenging sites were the river and paddy field $(n=4$, $20 \%)$, or pond and paddy field $(n=2,10 \%)$. Access to sunlight was available in $50 \%$ of the duck sheds while $20 \%$ of the farms reported the interface of ducks' scavenging area with wild animals/birds. The majority of the farms $(\mathrm{n}=17,85 \%)$ used duck manure as fish feed in their ponds. However, all the farms used antimicrobial agents of different kinds, including gentamycin (50\%), enrofloxacin $(30 \%)$ and oxytetracycline $(20 \%)$, while $60 \%$ of the farms applied vaccines against common duck diseases (duck plague and duck cholera).

Concerning hygiene practices, regular cleaning of the feeder and drinker was practiced in $40 \%(n=8)$ of the farms. Among the selected duck farms, floor cleaning of duck sheds was practiced on a daily $(70 \%, \mathrm{n}=14)$, weekly $(5 \%, \mathrm{n}=1)$, and monthly $(10 \%, \mathrm{n}=2)$ basis, and notably, $47 \%(n=8)$ farms did not use disinfectant for cleaning purposes. Majority of the farmers $(n=17,85 \%)$ washed hand with soap after contact with duck and handling of sick duck was avoided in $70 \%(\mathrm{n}=14)$ farms (see Additional file 5 showing variations in anthropogenic factors and environmental conditions).

Comparison with individual factors of farm management and environmental conditions with the isolation results of Campylobacter spp. revealed that source of drinking water, wet or dryness of duck shed, the practice of utensil cleaning, and flock age have profound impact $(\mathrm{p}<0.0005)$ on the overall occurrence of Campylobacter spp. in duck farm samples (Fig. 4A). Among other factors, handwashing practice, and sunlight access to the resting place of the ducks were also observed to influence the bacterial preponderance but in less magnitude. Considering the influence of drinking water source, reduction in Campylobacter occurrence for using tube-well water in comparison to river water was observed to be highly significant $(\mathrm{p}<0.0005)$ in cloacal swab samples and significant $(\mathrm{p}<0.005)$ in egg surface swab and drinking water samples but insignificant for soil samples (Fig. 4B). As potential drivers, the wet condition of duck shed and irregularity in utensil cleaning were observed to induce Campylobacter occurrence in a similar fashion, highly significantly $(\mathrm{p}<0.0005)$ in the cloacal swab, significantly $(\mathrm{p}<0.005)$ in egg swab and with marginal significance $(\mathrm{p}<0.05)$ for drinking water samples, but no such influence for soil samples (Fig. 4C and E). As a potential intervention, regular handwashing was found to be significant $(\mathrm{p}<0.05)$ in reducing the risk of Campylobacter incidence in cloacal swab samples. Association with Campylobacter incidence of flock age 1-6 month and insufficient access to sunlight was found to be marginally significant for cloacal swab samples but not in other kinds of samples (Fig. 4F and G). Detail statistical information of the Chisquare tests observing the association of a particular factor of farm management with Campylobacter occurrence in different sample types are included in Additional file 6.

\section{Discussion}

Being the major reservoirs of Campylobacter spp., poultry and livestock are mainly accountable for the continuing transmission of campylobacteriosis throughout the world. Among the agro-based enterprises, the poultry sector has been rapidly increasing, with an annual growth rate of $15-20 \%$ per annum, in densely-populated Bangladesh [38]. Duck farming is not only a promising livelihood alternative for the poverty-ridden communities in this country but also an important mean to enrich food security, particularly, in rural areas where plantorigin protein production is still challenging [39]. However, the rearing of ducks, an important reservoir for Campylobacter species, may impose an impending risk to public health. Recent studies have confirmed a close link between gastrointestinal disorders, caused by pathogenic microbes, including Campylobacter spp., with the pervasive incidence of malnutrition, particularly among children under 5 years, in Bangladesh and other developing countries [40]. Apart from the high prevalence of malnutrition, a rapid increase in disease incidences caused by MDR pathogens is the most challenging threat to public health in this developing nation with an agro-based economy. The large-scale use of antimicrobial agents, mostly in an imprudent manner, in the rapidly growing poultry sector is an important cause of MDR infections. The present study provides an insight into the occurrence, antimicrobial resistance traits, and potential risks of Campylobacter spp. associated with duck farming in Bangladesh, which could be credited as the first of its kind.

This survey has investigated the occurrence and its associated factors of Campylobacter in scavenging duck farms. The overall occurrence of Campylobacter spp. observed for the selected farms in this study is in congruence with a number of previous studies [41, 42]. However, in comparison to this study, there are reports of a higher incidence of Campylobacter occurrence in duck samples $[43,44]$. The observed dominance of C. coli (ca. 61\%) than C. jejuni (ca. 39\%) in duck samples indicates a hostspecific adaptive advantage of the former bacteria and in accordance with a number of previous investigations $[43,45]$. There are also reports of a higher prevalence of C. jejuni than C. coli in duck samples [46-48]. Recent 

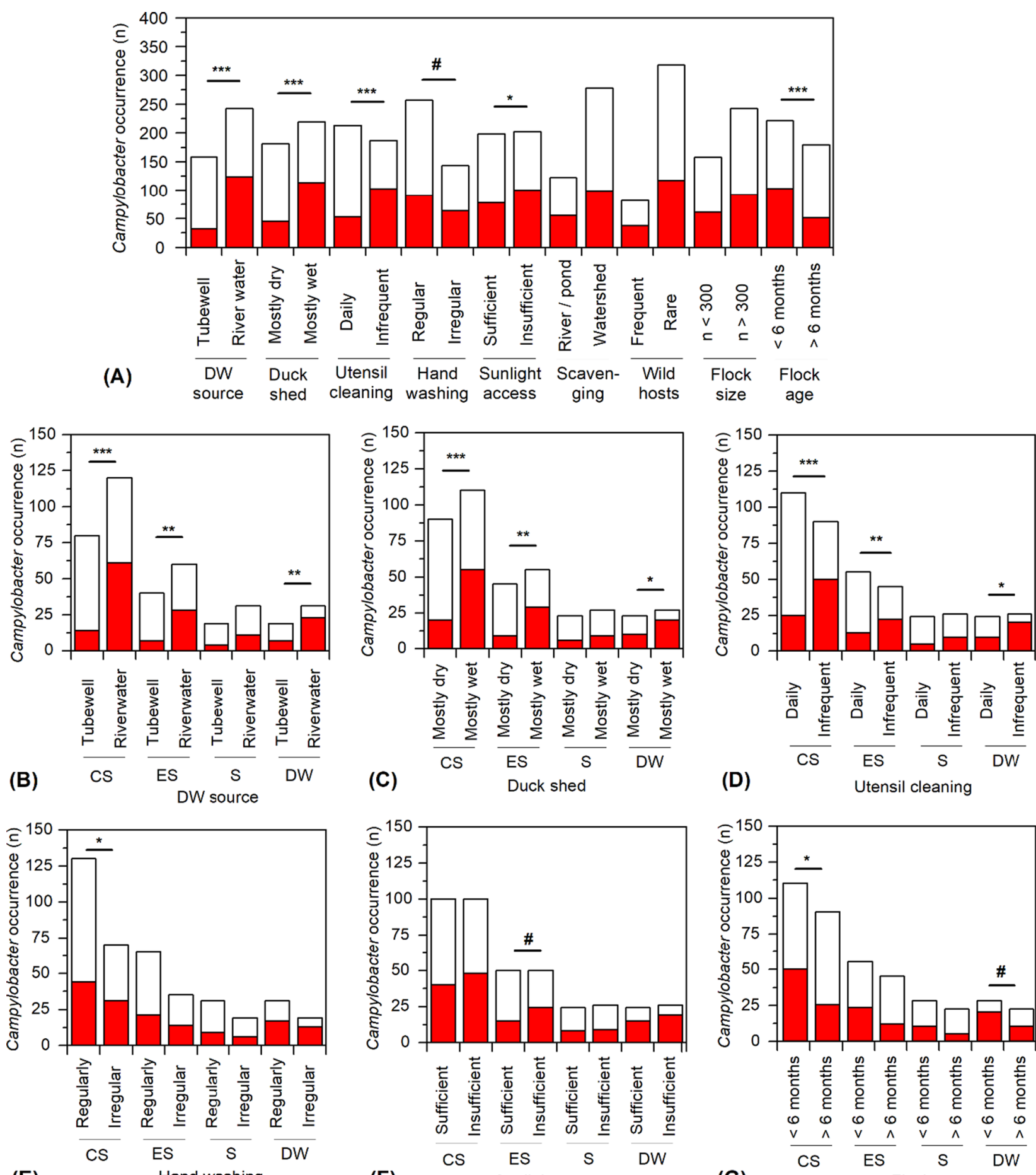

(E)

Hand washing

(F)

Sunlight access

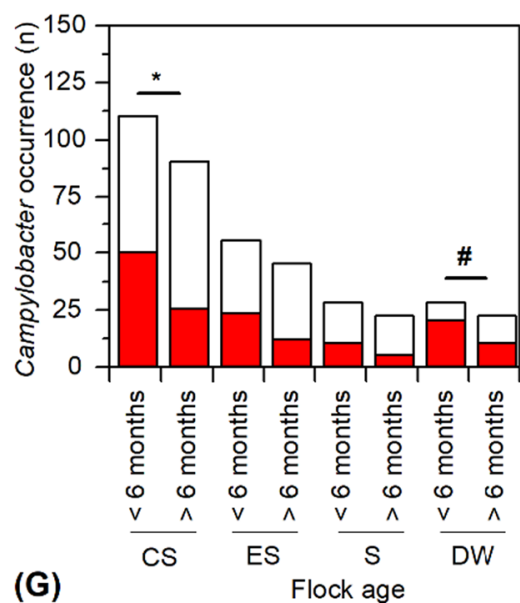

Fig. 4 Occurrence of Campylobacter spp. in different samples of the selected duck farms in relation to the variable management practices. A Variation in the overall occurrence of Campylobacter spp. under various categories of farm management practices. B-G Influences of each of the potential driving factors on the occurrence of Campylobacter spp. in different sample types. CS, ES, S, and DW indicate the types of samples, i.e., cloacal swab, egg surface swab, the soil of the duck resting places, and drinking water, respectively. The filled and unfilled portions in the stacked bars of each column represent the number of samples (n) detected positive and negative, respectively, for the occurrence of Campylobacter spp. A Chi-square test was performed to determine the significant association between Campylobacter occurrence and each of the driving factors. ${ }^{* * *}$, **, *, and \# indicate $p$ values of $<0.0005,<0.005,<0.05$, and $<0.1$, respectively. Details of statistical information are included in Additional file 6 
surveillance conducted in China has observed an overall prevalence of Campylobacter spp. in $33.5 \%$ of duck samples, similar to this study, but co-dominance of both C. jejuni and C. coli (ca. 49 and 47\%, respectively) [49]. These variations could be attributable to the differences in climatic settings, sample types, and analytical methods [50].

In the poultry production and supply chain, a frequent occurrence of MDR strains of Campylobacter has been reported worldwide [51, 52]. Unwise applications of antimicrobial agents exert selective pressure on the exposed bacterial populations for the evolvement of resistant traits. The occurrence of MDR strains of Campylobacter spp. is primarily accredited to the large-scale and imprudent use of a variety of antimicrobials in the poultry and livestock sectors. In Bangladesh, antimicrobials are indiscriminately used by the poultry farmers, a vast majority of them following the biased instructions from the feed and chick traders, and their associated suppliers of antimicrobial agents [53]. Likewise, a large fraction of C. jejuni and C. coli populations in duck farms in this study has been observed as resistant to commonly used antimicrobials, e.g., amoxicillin, erythromycin, streptomycin, and tetracycline. Depending on variable geosocio-climatic conditions, diverse patterns of resistance traits, e.g., a low frequency of erythromycin resistance but the high occurrence of resistance to ciprofloxacin and tetracycline among Campylobacter isolates from duck or poultry samples in Malaysia and Italy, have been noted [44, 54]. Considering the 'One health' perspective [53], the occurrence of MDR strains among ca. 37 and $42 \%$ of the $C$. coli and C. jejuni isolates, respectively, in the duck farm samples point out an alarming situation. Notably, health hazards from zoonotic infections by some of these MDR strains showing full or intermediate resistance to all major kinds of antimicrobials, including $\beta$-lactam, aminoglycoside, quinolone, and macrolide, is very problematic. A similar situation has been reported for the prevalent Campylobacter populations in chicken farms in the study region [11]. Although detected as comparatively less abundant than C. coli, the occurrence of MDR traits in equivalent or higher frequency in $C$. jejuni strains isolated from the duck farms (Table 2) could be related to the natural overwhelming predominance of the latter species in broiler meats and other poultry products and human campylobacteriosis [15, 40, 54]. Notwithstanding is the observed similarity in the percentage occurrence of different resistance traits between $C$. jejuni and $C$. coli strains (Fig. 2), indicating a salient role of horizontal gene transfer between these two species. MDR traits in Campylobacter strains are often linked to the presence of multiple resistant genes in large mobile elements (e.g., plasmids, Class I integron, conjugative transposon) in the bacterial genome [55]. Mutations or modulations in a number of genes regulating efflux pump systems, e.g., gyrA and gyrB of DNA gyrase, parC, and parE of topoisomerase IV, and the $c m e B$ gene of the CmeABC multidrug efflux pump have been also shown to confer MDR traits, including resistance to fluoroquinolones, in Campylobacter spp. [56].

Occurrence in a portion of C. jejuni and C. coli strains of intermediate resistance for fluoroquinolones, azithromycin, and erythromycin can be attributable to the natural decay of their active components, and bacterial exposure to sub-lethal concentration of these compounds [11]. Antimicrobial residues, at subinhibitory concentrations, can trigger different biological effects, such as stress response, enhanced mutation rate, or genetic recombination events in bacterial populations, therefore, may have salient impacts to our gut flora [57]. Unfortunately, the residual content of commonly used antimicrobials, including fluoroquinolones, has been reported for the majority of broiler meats and livers in Bangladesh [11].

The transmission dynamics of antimicrobial-resistant bacteria to humans are related to the consumption of contaminated animal-source food, direct contact with animals, and exposure to contaminated environmental sources such as water and dust [58]. As noted in PE surveillance of this study, the large-scale use of antimicrobial agents in all the study farms, in combination with the extensive use of duck manure for aquaculture production may impose increased vulnerability to MDR pathogens among the local residents. Contamination with Campylobacter spp., including their MDR strains, of natural surface waters serving as a major source of drinking water for the reared ducks could be linked to the discarded duck feces. However, this could explain only partially the observed occurrence and diversity in antimicrobial resistance of Campylobacter spp., taking into account the reported use of antimicrobials at the study farms. For example, resistance to amoxicillin, erythromycin and streptomycin were observed for a vast majority of the isolated strains did not match with the antimicrobial agents applied most frequently (gentamicin, tetracycline, and fluoroquinolones) at the duck farms. Therefore, it could be assumed that allochthonous factors, including droppings from wild birds, and input of sewage materials from poultry farms nearby, play an integral role in the dynamics and resistance traits of Aeromonas spp. in natural surface waters, which are used without any treatment as drinking water in the majority of duck farms. The MDR traits prevalent among the Aeromonas strains in sources of drinking water may eventually correlate to the bacterial resistance patterns in the duck samples. 
Analyses made in this study demonstrates that using of water from rivers or ponds rather than tube-well is significantly associated with the Campylobacter occurrence in not only DW but also in CS and ES samples, i.e., water pre-contaminated at natural reservoirs is a dominant factor linked to the bacterial preponderance in duck samples. This is in congruence with the relatively low dieoff rate of Campylobacter in water [59]. The widespread occurrence of thermotolerant Campylobacter in natural surface waters is largely attributable to the frequent contamination of aquatic ecosystems with feces of the reservoir animals, including wild birds, and run-off from poultry farms or sewage [60]. Potable drinking waters can be also contaminated in the farm environment due to a lack of regular hygienic practices, particularly, utensil cleaning, and significantly influence Campylobacter incidences in CS and ES samples (Fig. 4). Insufficient disinfection treatment of drinking water has been recognized as a significant driver of Campylobacter incidence in the production and supply chain of broiler chicken [11, 26]. Based on the results of this study, decontaminating drinking water before serving to the reared ducks, and proper treatment of duck waste products before discarding them to adjacent aquatic ecosystems could be distinguished as important interventions to reduce the risk of MDR infections caused by Campylobacter spp. derived from the duck farms.

Variation in the monthly occurrence of Campylobacter spp. in the farm samples of this study could be linked to the variable amplitude of climatic factors. Particularly, a significant role of increased temperature and humidity in stimulating the bacterial occurrence was discernible. Campylobacter colonization in the intestine and caeca of chicken is reported to fluctuate with seasonal variation in temperature [12]. A significant increase in the incidences of Campylobacter infection during the summer months has been reported for many countries, particularly in the temperate region [16]. However, the observed negative influence of increased sunshine hour on Campylobacter occurrence in duck farm samples could be related to retardation of the bacterial populations with intensified ultraviolet radiation [61]. On the other hand, a correlation between high humidity and increased Campylobacter occurrence observed for the duck farm samples in this study is in agreement with results from clinical surveillance and broiler farms $[14,62]$. Increased precipitation and relative humidity can aid to prolonged persistence of Campylobacter spp. in the environment since the bacteria is sensitive to dry conditions [14]. A positive influence of increased rainfall on Campylobacter incidence in the farm samples was also evident from this study, although a drastic decrease in the bacterial occurrence during July (Fig. 2) could be attributable to the dilution impact of high precipitation events. Elucidated influences of multiple climatic factors on Campylobacter occurrence may not always be discernible since the inferences are based on short-term observations. Previous investigations at different geo-socio-climatic settings noted that the bacterial infection dynamics could partially correlate to the climatic factors $[63,64]$. Nonetheless, the estimated regulation of each of the climatic drivers provides a basis to predict the bacterial dynamics in duck farms.

In densely-populated countries like Bangladesh, proper implementation of management strategies to minimize the risks of Campylobacter and other zoonotic infections from the growing poultry industries are crucial. Concerning environmental management, remarkable is the observed significance between Campylobacter occurrence and persistence of wet condition, and insufficient sunlight in duck sheds, which also support the inferences made for climatic influences on the bacterial dynamics. As discussed above, using untreated natural surface water as drinking water, infrequent cleaning of utensils, and inadequate application of disinfectants are potential risk factors of Campylobacter occurrence in duck farms. Farm managers should also think of intervention strategies considering the age-specific variable susceptibility of ducks to Campylobacter infection. Chicken flocks aged $>30$ days are considered more susceptible to Campylobacter infection than younger chicks at broiler farms in the study region [26]. Interestingly, the results of this study indicate that older ducks above 6 months are a less potent reservoir of the bacteria. Although not evident from the observations made in this study, a larger flock size ( $>1500$ birds) of poultry animals could be occasionally important determinant of higher Campylobacter occurrence [26].

Adoption of proper management practices for not only duck rearing but also maintaining a healthy environment is largely credited to the enriched knowledge and educational status of the farmers. Sociodemographic information obtained in this study showed that most of the farmers lacked training on duck rearing methods and many of them discontinued formal education (Additional file 4). These lacking in education and learning-based improved knowledge could have indulged inadequate management practices among the majority farmers favoring the enhanced incidence of Campylobacter occurrence in the duck farms. A recent surveillance study in Bangladesh has also reported that persons having a long term (10 years or more) experience in poultry farming and graduate-level education, are more likely to use antimicrobial agents in a wise manner [65]. Unfortunately, the majority of the duck rearers in this study had the farming experience of fewer than 5 years and none had completed graduate-level education. Imprudent application 
of antimicrobial agents in the study farms could be also attributable to the lack of animal health care following guidelines of the registered veterinarians, as reported by a vast majority $(80 \%)$ of the duck rearers, Moreover, these farmers did not receive any training on biosecurity measures that could play a significant role in limiting their large-scale application of antimicrobial agents, and disposal of fecal waste from the reared ducks into natural water reservoirs and adopting other environmental interventions or protective measures to minimize the risk of occurrence, and dissemination of MDR strains of Campylobacter spp.

An important recent strategy to ensure food safety is the "farm to fork" approach including a comprehensive understanding of the hazards and control points at all stages of the food production and supply chain. Therefore, proper tackling of Campylobacter infections would require holistic understanding of the interactive linkages of disease epidemiology with bacterial transmission dynamics, associated environmental drivers and anthropogenic practices at poultry farms. Inferences made in this study on potential sources and risk factors of Campylobacter occurrence would lead to formulating an integrated management approach to prevent or control Campylobacter infection from ducks reared in homestead farms. However, analysis of larger samples through a logistic regression model could signify the correlation between the risk factors and Campylobacter occurrence. In conjunction, case-control studies comparing the occurrence and genetic traits of potentially harmful Campylobacter spp. in ducks and among the infected human populations would provide more insights into the extent of the associated socio-environmental determinants.

\section{Conclusion}

Results obtained in this study show that duck farms are a potential source of Campylobacter spp. and may contribute to the incidences of human campylobacteriosis in Bangladesh. The occurrence of C. coli and C. jejuni in duck farms is influenced by a combined interaction of environmental and anthropogenic factors. Among the climatic variables, temperature and humidity are the major drivers of Campylobacter dynamics. Untreated natural surface water, if used as drinking water for the ducks contributes significantly to the increased occurrence of Campylobacter spp. An important concern is that a large number of $C$. jejuni and $C$. coli strains have become resistant to multiple antimicrobials. Anthropogenic interventions including regular cleaning of utensils, frequent hand washing, provision of sufficient ventilation, and sunlight access are inferred as potentially preventive to Campylobacter infections. The study also suggests an inherent need for awareness building among the farmers to promote adequate practices regarding hygiene, water treatment, waste disposal, and adept use of antimicrobial agents to reduce the spread of MDR Campylobacter and health hazards associated with duck farming. Therefore, proper tackling of Campylobacter infections in humans would require not only detailed information on disease epidemiology but also a holistic understanding on how the bacterial transmission dynamics are influenced by the combined impacts of climatic, anthropogenic, environmental factors. Future research should focus on horizontal transfer of pathogenic traits among Campylobacter strains isolated from ducks, poultry, wild avian fauna, and human populations and explore comparative genome analysis tools at the environmenthuman-animal interfaces.

\section{Abbreviations}

BBA: Blood agar base no.2; Cl: Confidence interval; FGD: Focus group discussion; IQR: Interquartile range; MDR: Multi drug resistance; PCR: Polymerase chain reaction; PE: Participatory epidemiology; CS: Cloacal swab; ES: Egg surface swab; S: Soil of the duck resting places; DW: Drinking water; F: Feed; AMX: Amoxicillin; AZM: Azithromycin; CIP: Ciprofloxacin; ERY: Erythromycin; GEN: Gentamycin; NOR: Norfloxacin; STR: Streptomycin; TET: Tetracycline.

\section{Supplementary Information}

The online version contains supplementary material available at https://doi. org/10.1186/s12879-021-06834-w.

Additional file 1. Questionnaire for assessment of sociodemographic information, farm management and hygienic practices in semi-scavenging duck farms at Mymensingh district of Bangladesh.

Additional file 2. Representative gel images with PCR-amplicons detecting Campylobacter genus by 16S rRNA gene-based PCR, and the predominant species, C. jejuni and C. coli, by hipO gene-, and cdtC genebased PCR assays.

Additional file 3. Variation in monthly isolation rate of Campylobacter spp. in different samples collected from the selected duck farms.

Additional file 4. Sociodemographic status of duck rearers $(N=57)$ at selected duck farms in Bangladesh.

Additional file 5. Status of farm management operations, hygiene and sanitation practices at selected duck farms $(n=20)$ in Bangladesh.

Additional file 6. Probable role of anthropogenic and environmental factors on the occurrence of Campylobacter spp.

\section{Acknowledgements}

The microbiological surveillance was part of the MS thesis of MNU, Department of Microbiology and Hygiene, Bangladesh Agricultural University. Authors gratefully acknowledge the support of Professor Dr. Shinji Yamasaki, Graduate School of Life and Environmental Sciences, Osaka Prefecture University, Osaka, Japan who provided the microaerophilic gas packs used in this research work

\section{Authors' contributions}

SMLK, SBN, and JF designed the study. MNU collected the respondent data and samples from the field and performed microbiological analysis. SBN, MNU, and SSI analyzed the data and prepared the draft manuscript. SMLK, SBN, MSRK, and SY supervised the study programs, provided technical support, and finalized the manuscript. All authors read and approved the final manuscript. 


\section{Funding}

The part of this work was supported by the Grants from Ministry of Science and Technology, Government of the People's Republic of Bangladesh, Bangladesh Secretariat, Dhaka-1000, Bangladesh (Project No. 2017-18/420/MoST).

\section{Availability of data and materials}

All datasets analyzed during this research are included in this published article [and its Additional files]. Detail information on the datasets and materials used in this study are available from the corresponding author on reasonable request. Confidentiality of data is maintained anonymously.

\section{Declarations}

\section{Ethics approval and consent to participate}

Informed consent was obtained from all participants or, if subjects were under 18 years old, from their parent or legal guardian before conducting participatory epidemiological methods. Verbal consent was also obtained from the farm owners prior to collecting samples for microbiological analysis at the selected sites. Although no animal intervention was needed, the methodological procedures were performed in consultation with the local livestock authorities. The study was carried out in compliance with the ARRIVE guidelines. Ethical approvals concerning the involvement of humans and animals in the study were obtained under reference no. AWEEC/BAU/2019(46H) and AWEEC/BAU/2019(46A), respectively, from the Ethical Committee of the Bangladesh Agricultural University. We confirm that all methods were carried out in accordance with relevant guidelines and regulations for the research article.

\section{Consent for publication}

Not applicable.

\section{Competing interests}

The authors declare that they have no competing interests in this section.

\section{Author details}

1 Department of Microbiology and Hygiene, Bangladesh Agricultural University, Mymensingh 2202, Bangladesh. ${ }^{2}$ Graduate School of Life and Environmental Sciences, Osaka Prefecture University, Osaka 598-8531, Japan. ${ }^{3}$ Department of Pharmacology, Bangladesh Agricultural University, Mymensingh 2202, Bangladesh.

Received: 8 November 2020 Accepted: 29 October 2021

Published online: 07 November 2021

\section{References}

1. Islam MA, Howlider MAR, Alam MA, et al. Present status, problem and prospect of duck farming in rural areas of Mymensingh district, Bangladesh. Asian J Med Biol Res. 2016;2(2):202-12. https://doi.org/10.3329/ ajmbr.v2i2.29062.

2. Hoque MA, Skerratt LF, Cook AJC, et al. Factors limiting the health of semiscavenging ducks in Bangladesh. Trop Anim Health Prod. 2011;43(2):44150. https://doi.org/10.1007/s11250-010-9712-1.

3. Colles FM, Ali JS, Sheppard SK, et al. Campylobacter populations in wild and domesticated Mallard ducks (Anas platyrhynchos). Environ Microbiol Rep. 2011;3(5):574-80. https://doi.org/10.1111/j.1758-2229.2011.00265.x.

4. Kim JK, Negovetich NJ, Forrest HL, et al. Ducks: the "Trojan horses" of H5N1 influenza. Influenza Other Respir Viruses. 2009;3(4):121-8. https:// doi.org/10.1111/j.1750-2659.2009.00084.x.

5. Nachamkin I. Campylobacter and Arcobacter. In: Murray PR, Baron EJ, Jorgensen JA, editors. Manual of clinical microbiology. 8th ed. Washington DC: ASM press; 2003. p. 902-14.

6. Neogi PK, Shahid NS. Serotypes of Campylobacter jejuni isolated from patients attending a diarrhoeal disease hospital in urban Bangladesh. J Med Microbiol. 1987;24(4):303-7. https://doi.org/10.1099/00222 615-24-4-303.

7. Nielsen EM, Engberg J, Madsen M. Distribution of serotypes of Campylobacter jejuni and C. coli from Danish patients, poultry, cattle and swine. FEMS Immunol Med Microbiol. 1997;19(1):47-56. https://doi.org/10. 1111/j.1574-695X.1997.tb01071.x.
8. European Centre for Disease Prevention and Control. Campylobacteriosis. In: ECDC. Annual epidemiological report for 2017. Stockholm: ECDC; 2019. https://www.ecdc.europa.eu/en/publications-data/campylobac teriosis-annual-epidemiological-report-2017.

9. Skarp CPA, Hänninen ML, Rautelin H, et al. Campylobacteriosis: the role of poultry meat. Clin Microbiol Infect. 2016;22(2):103-9. https://doi.org/10. 1016/j.cmi.2015.11.019.

10. Kabir SML, Islam I, Suman MH, et al. Isolation, identification and antimicrobial susceptibility profiles of Campylobacter spp. with assessment of their risk factors in broiler flocks of Bangladesh Agricultural University Poultry Farm. J Basic Appl Sci Res. 2014;4(7):160-8.

11. Neogi SB, Islam MM, Islam SS, et al. Risk of multi-drug resistant Campylobacter spp and residual antimicrobials at poultry farms and live bird markets in Bangladesh. BMC Infect Dis. 2020;20:278. https://doi.org/10. 1186/s12879-020-05006-6.

12. Wallace JS, Stanley KN, Currie JE, et al. Seasonality of thermophilic Campylobacter populations in chickens. J Appl Microbiol. 1997;82(2):219-24.

13. Lake IR, Colón-González FJ, Takkinen J, et al. Exploring Campylobacter seasonality across Europe using The European Surveillance System (TESSy), 2008 to 2016. Euro Surveill. 2019;24(13):1800028. https://doi.org/10.2807/ 1560-7917.ES.2019.24.13.180028.

14. Patrick ME, Christiansen LE, Wainø M, et al. Effects of climate on incidence of Campylobacter spp. in humans and prevalence in broiler flocks in Denmark. Appl Environ Microbiol. 2004;70(12):7474-80. https://doi.org/ 10.1128/AEM.70.12.7474-7480.2004.

15. Jore S, Viljugrein H, Brun E, et al. Trends in Campylobacter incidence in broilers and humans in six European countries, 1997-2007. Prev Vet Med. 2010;93(1):33-41. https://doi.org/10.1016/j.prevetmed.2009.09.015.

16. Djennad A, Lacono GL, Sarran C, et al. Seasonality and the effects of weather on Campylobacter infections. BMC Infect Dis. 2019;19:255. https://doi.org/10.1186/s12879-019-3840-7.

17. Abraham S, Sahibzada S, Hewson K, et al. Emergence of fluoroquinolone resistant Campylobacter jejuni and Campylobacter coli among Australian chickens in the absence of fluoroquinolone use. Appl Environ Microbiol. 2020;86(8):e02765-e2819. https://doi.org/10.1128/AEM.02765-19.

18. Ibrahim JN, Eghnatios E, El Roz A, et al. Prevalence, antimicrobial resistance and risk factors for campylobacteriosis in Lebanon. J Infect Dev Ctries. 2019;13(1):11-20. https://doi.org/10.3855/jidc.10729.

19. Pollett $S$, Rocha C, Zerpa R, et al. Campylobacter antimicrobial resistance in Peru: a ten-year observational study. BMC Infect Dis. 2012;12:193. https://doi.org/10.1186/1471-2334-12-193.

20. Mukherjee P, Ramamurthy T, Mitra U, et al. Emergence of high-level azithromycin resistance in Campylobacter jejuni isolated from Paediatric Diarrhoea cases in Kolkata, India. Antimicrob Agents Chemother. 2014;58(7):4248-4248. https://doi.org/10.1128/AAC.02931-14.

21. Department of Livestock Services, Ministry of Fisheries and Livestock, Government of the Peoples' Republic of Bangladesh. Animal Feed Act. 2010;1-9. http://www.dls.gov.bd.

22. Ahmed D, Hoque A, Elahi MSB, et al. Bacterial aetiology of diarrhoeal diseases and antimicrobial resistance in Dhaka, Bangladesh, 2005-2008. Epidemiol Infect. 2012;140(9):1678-84.

23. Kabir SML, Lubna MM, Islam M, et al. Isolation, molecular identification and antimicrobial resistance patterns of Campylobacter species of dairy origin: first report from Bangladesh. Vet Sci Dev. 2018;8:7838. https://doi. org/10.4081/vsd.2018.7838.

24. Karmaker S, Kabir SML, Haque AKMZ, et al. Screening of human diarrhoeal samples in Mymensingh city of Bangladesh for the isolation, identification and antimicrobial resistance profiles of Campylobacter spp. Afr J Microbiol Res. 2018;12(32):771-8. https://doi.org/10.5897/AJMR2 018.8946.

25. Barrios PR, Reiersen J, Lowman R, et al. Risk factors for Campylobacter spp. colonization in broiler flocks in Iceland. Prev Vet Med. 2006;74(4):264-78. https://doi.org/10.1016/j.prevetmed.2005.12.003.

26. Hasan MM, Talukder S, Mandal AK, et al. Prevalence and risk factors of Campylobacter infection in broiler and cockerel flocks in Mymensingh and Gazipur districts of Bangladesh. Prev Vet Med. 2020;180: 105034. https://doi.org/10.1016/j.prevetmed.2020.105034.

27. Thrusfield M. Veterinary epidemiology. Oxford: Blackwell Publishing; 2009. p. 228-46.

28. Shiramaru S, Asakura M, Inoue $\mathrm{H}$, et al. A cytolethal distending toxin gene-based multiplex PCR assay for detection of Campylobacter spp. in 
stool specimens and comparison with culture method. J Vet Med Sci. 2012;74(7):857-62. https://doi.org/10.1292/jvms.11-0574.

29. Hoshino K, Yamasaki S, Mukhopadhyay AK, et al. Development and evaluation of a multiplex PCR assay for rapid detection of toxigenic Vibrio cholerae $\mathrm{O} 1$ and 0139 . FEMS Immunol Med Microbiol. 1998;20(3):201-7. https://doi.org/10.1111/j.1574-695X.1998.tb01128.x.

30. Samosornsuk W, Asakura M, Yoshida E, et al. Evaluation of a cytolethal distending toxin (cdt) gene-based species-specific multiplex PCR assay for the identification of Campylobacter strains isolated from poultry in Thailand. Microbiol Immunol. 2007;51(9):909-17. https://doi.org/10. 1111/j.1348-0421.2007.tb03974.x.

31. Linton D, Lawson AJ, Owen RJ, et al. PCR detection, identification to species level, and fingerprinting of Campylobacter jejuni and Campylobacter coli direct from diarrheic samples. J Clin Microbiol. 1997;35(10):2568-72. https://doi.org/10.1128/JCM.35.10.2568-2572. 1997.

32. Asakura M, Samosornsuk W, Hinenoya A, et al. Development of a cytolethal distending toxin (cdt) gene-based species-specific multiplex PCR assay for the detection and identification of Campylobacter jejuni, Campylobacter coli and Campylobacter fetus. FEMS Immunol Med Microbiol. 2008;52(2):260-6. https://doi.org/10.1111/j.1574-695X.2007. 00369.x.

33. Clinical and Laboratory Standards Institute (CLSI). Performance Standards for Antimicrobial Susceptibility Testing (26th ed). CLSI supplement M100S. Wayne. 2016;1-256.

34. Catley A, Alders RG, Wood JL. Participatory epidemiology: approaches, methods, experiences. Vet J. 2012;191(2):151-60. https://doi.org/10. 1016/j.tvjl.2011.03.010.

35. Carrique-Mas JJ, Bryant JE, Cuong NV, et al. An epidemiological investigation of Campylobacter in pig and poultry farms in the Mekong delta of Vietnam. Epidemiol Infect. 2014;142(7):1425-36. https://doi.org/10. 1017/S0950268813002410.

36. Centers for Disease Control and Prevention (CDC).2012. Epi Info 7. User Guide. Available from: http://www.cdc.gov/epiinfo.

37. Magiorakos AP, Srinivasan A, Carey RB, et al. Multidrug-resistant, extensively drug-resistant and pandrug-resistant bacteria: an international expert proposal for interim standard definitions for acquired resistance. Clin Microbiol Infect. 2012;18(3):268-81. https://doi.org/10.1111/j. 1469-0691.2011.03570.x.

38. Rahman MS, Jang DH, Yu CJ. Poultry industry of Bangladesh: entering a new phase. Korean J Agril Sci. 2017;44(2):272-82. https://doi.org/10. 7744/kjoas.20170027.

39. Hossain M, Hoque M, Giorgi E, et al. Nutritional benefits of improving small-scale livestock rearing practices-a One-Health cluster-randomised controlled trial in Bangladesh. SSRN Electron J. 2018. https:// doi.org/10.2139/ssrn.3289790.

40. Platts-Mills JA, Kosek M. Update on the burden of Campylobacter in developing countries. Curr Opin Infect Dis. 2014;27(5):444. https://doi. org/10.1097/QCO.0000000000000091.

41. McCrea BA, Tonooka KH, VanWorth C, et al. Prevalence of Campylobacter and Salmonella species on farm, after transport, and at processing in specialty market poultry. Poult Sci. 2006;85(1):136-43. https://doi. org/10.1093/ps/85.1.136.

42. Rahimi E, Alian F. Prevalence and characteristic of Campylobacter species isolated from raw duck and goose meat in Iran. IPCBEE. 2011;9:171-5.

43. Little CL, Richardson JF, Owen RJ, et al. Prevalence, characterization and antimicrobial resistance of Campylobacter and Salmonella in raw poultry meat in the UK, 2003-2005. Int J Environ Health Res. 2008;18(6):403-14. https://doi.org/10.1080/09603120802100220.

44. Adzitey F, Rusul G, Huda N, et al. Prevalence, antibiotic resistance and RAPD typing of Campylobacter species isolated from ducks, their rearing and processing environments in Penang, Malaysia. Int J Food Microbiol. 2012;154(3):197-205. https://doi.org/10.1016/j.jfoodmicro. 2012.01.006.

45. Boonmar S, Yingsakmongkon S, Songserm T, et al. Detection of Campylobacter in duck using standard culture method and multiplex polymerase chain reaction. Southeast Asian J Trop Med Public Health. 2007;38(4):728-31.

46. Nonga HE, Muhairwa AP. Prevalence and antibiotic susceptibility of thermophilic Campylobacter isolates from free range domestic duck (Cairina moschata) in Morogoro municipality. Tanzania Trop Anim Health Prod. 2010;42(2):165-72. https://doi.org/10.1007/ s11250-009-9401-0.

47. Wei B, Se-Yeoun C, Min K, et al. Antimicrobial susceptibility profiles and molecular typing of Campylobacter jejuni and Campylobacter coli isolates from ducks in South Korea. Appl Environ Microbiol. 2014;80(24):7604-10. https://doi.org/10.1128/AEM.02469-14.

48. Saengthongpinit C, Nane-Siri D, Aparachita P, et al. Longitudinal study of Salmonella and Campylobacter species from two laying duckling flocks in the central region of Thailand. Thai J Vet Med. 2014;44(3):355-61.

49. Han X, Guan X, Zeng H, Li J, Huang X, Wen Y, Zhao Q, Huang X, Yan Q, Huang Y. Prevalence, antimicrobial resistance profiles and virulenceassociated genes of thermophilic Campylobacter spp. isolated from ducks in a Chinese slaughterhouse. Food Control. 2019;104:157-66. https://doi.org/10.1016/j.foodcont.2019.04.038.

50. Abulreesh HH, Paget TA, Goulder R. Campylobacter in waterfowl and aquatic environments: incidence and methods of detection. Environ Sci Technol. 2006;40(23):7122-31. https://doi.org/10.1021/es060327l.

51. Zhao S, Young SR, Tong E, et al. Antimicrobial resistance of Campylobacter isolates from retail meat in the United States between 2002 and 2007. Appl Environ Microbiol. 2010;76(24):7949-56. https://doi.org/10. 1128/AEM.01297-10.

52. Han X, Zhu D, Lai H, et al. Prevalence, antimicrobial resistance profiling and genetic diversity of Campylobacter jejuni and Campylobacter coli isolated from broilers at slaughter in China. Food Control. 2016;69:16070. https://doi.org/10.1016/j.foodcont.2016.04.051.

53. Masud AA, Rousham EK, Islam MA, et al. Drivers of antibiotic use in poultry production in Bangladesh: dependencies and dynamics of a patron-client relationship. Front Vet Sci. 2020;7:78. https://doi.org/10. 3389/fvets.2020.00078.

54. Marotta F, Garofolo G, Di Marcantonio L, et al. Antimicrobial resistance genotypes and phenotypes of Campylobacter jejuni isolated in Italy from humans, birds from wild and urban habitats, and poultry. PLoS ONE. 2019;14(10): e0223804. https://doi.org/10.1371/journal.pone. 0223804.

55. Hernando-Amado S, Coque TM, Baquero F, Martínez JL. Defining and combating antibiotic resistance from One Health and Global Health perspectives. Nat Microbiol. 2019;4(9):1432-42. https://doi.org/10. 1038/s41564-019-0503-9.

56. Wieczorek K, Osek J. Antimicrobial resistance mechanisms among Campylobacter. BioMed Res Int. 2013;2013: 340605. https://doi.org/10. 1155/2013/340605.

57. Allen HK, Donato J, Wang HH, Cloud-Hansen KA, Davies J, Handelsman J. Call of the wild: antibiotic resistance genes in natural environments. Nat Rev Microbiol. 2010;8(4):251-9. https://doi.org/10.1038/nrmic ro2312.

58. Hoelzer K, Wong N, Thomas J, Talkington K, Jungman E, Coukell A. Antimicrobial drug use in food-producing animals and associated human health risks: what, and how strong, is the evidence? BMC Vet Res. 2017;13(1):1-38. https://doi.org/10.1186/s12917-017-1131-3.

59. Schang C, Lintern A, Cook PL, et al. Presence and survival of culturable Campylobacter spp. and Escherichia coli in a temperate urban estuary. Sci Total Environ. 2016;569-570:1201-11. https://doi.org/10.1016/j.scito tenv.2016.06.195.

60. Savill MG, Hudson JA, Ball A, et al. Enumeration of Campylobacter in New Zealand recreational and drinking waters. J Appl Microbiol. 2001;91(1):38-46. https://doi.org/10.1046/j.1365-2672.2001.01337.x.

61. Obiri-Danso K, Paul N, Jones K. The effects of UVB and temperature on the survival of natural populations and pure cultures of Campylobacter jejuni, Camp. coli, Camp. lari and urease-positive thermophilic Campylobacters (UPTC) in surface waters. J Appl Microbiol. 2001;90(2):256-67. https://doi.org/10.1046/j.1365-2672.2001.01239.x.

62. Line JE. Influence of relative humidity on transmission of Campylobacter jejuni in broiler chickens. Poult Sci. 2006;85(7):1145-50. https://doi. org/10.1093/ps/85.7.1145.

63. Bi P, Cameron AS, Zhang Y, Parton KA. Weather and notified Campylobacter infections in temperate and sub-tropical regions of Australia: an ecological study. J Infect. 2008;57(4):317-23. https://doi.org/10.1016/j. jinf.2008.08.004. 
64. Sterk A, Schijven J, de Roda Husman AM, et al. Effect of climate change on runoff of Campylobacter and Cryptosporidium from land to surface water. Water Res. 2016;95:90-102. https://doi.org/10.1016/j.watres. 2016.03.005.

65. Hassan MM, Kalam M, Alim M, Shano S, et al. Knowledge, attitude, and practices on antimicrobial use and antimicrobial resistance among commercial poultry farmers in Bangladesh. Antibiotics. 2021;10(7):784. https://doi.org/10.3390/antibiotics10070784.

\section{Publisher's Note}

Springer Nature remains neutral with regard to jurisdictional claims in published maps and institutional affiliations.
Ready to submit your research? Choose BMC and benefit from:

- fast, convenient online submission

- thorough peer review by experienced researchers in your field

- rapid publication on acceptance

- support for research data, including large and complex data types

- gold Open Access which fosters wider collaboration and increased citations

- maximum visibility for your research: over $100 \mathrm{M}$ website views per year

At BMC, research is always in progress.

Learn more biomedcentral.com/submissions 